\title{
The impact of electricity demand reduction policies on the EU-ETS: Modelling electricity and carbon prices and the effect on industrial competitiveness
}

a Wuppertal Institute for Climate, Environment and Energy, Germany

$\mathrm{b}$ Institute of Energy Economics/Ecofys, Germany

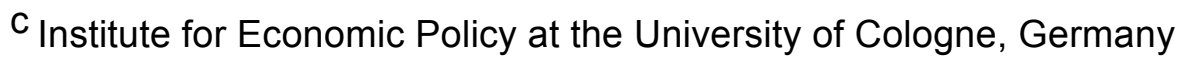

* Corresponding author

E-mail: johannes.thema@wupperinst.org

Originally published as:

Johannes Thema, Felix Suerkemper, Katharina Grave, Adrian Amelung (2013): The impact of electricity demand reduction policies on the EU-ETS: Modelling electricity and carbon prices and the effect on industrial competitiveness. In: Energy Policy (2013), online-first. Print version forthcoming. 


\title{
The impact of electricity demand reduction policies on the EU-ETS: Modelling electricity and carbon prices and the effect on industrial competitiveness
}

Johannes Thema, Felix Suerkemper, Katharina Grave, Adrian Amelung

\begin{abstract}
The European electricity market is linked to a carbon market with a fixed cap that limits greenhouse gas emissions. At the same time, a number of energy efficiency policy instruments in the EU aim at reducing the electricity consumption. This article explores the interactions between the EU's carbon market on the one hand and instruments specifically targeted towards energy end-use efficiency on the other hand. Our theoretical analysis shows how electricity demand reduction triggered by energy efficiency policy instruments affects the emission trading scheme: Without adjustments of the fixed cap, decreasing electricity demand reduces the carbon price without reducing total emissions. With lower carbon prices, costly low emission processes will be substituted by cheaper high emitting processes. Possible electricity and carbon price effects of electricity demand reduction scenarios under various carbon caps are quantified with a long-term electricity market simulation model. The results show that electricity efficiency policies allow for a significant reduction of the carbon cap: Compared to the 2005 emission level, $30 \%$ emission reductions can be achieved by 2020 within the emission trading scheme with similar or even lower costs for the industrial sector than were expected when the cap was initially set for a $21 \%$ emission reduction.
\end{abstract}

Keywords: Emission Trading Scheme (ETS); policy interaction; energy efficiency policy.

\section{Introduction}

The standard economic textbook argument is that carbon emission trading schemes (ETS) are a first-best climate policy instrument. Under perfect market conditions, allowances to emit greenhouse gases (GHG) would be allocated efficiently between obliged actors (Perman et al. 2011, Endres 2007, Fritsch 2011) and emissions reduced at least cost.

At the same time, the improvement of end-use energy efficiency (EE) is generally seen as the most cost-effective way to reduce CO2 emissions (McKinsey 2009, Wuppertal Institute et al. 2010, IEA 2010). However, many measures to reduce the energy demand through improved energy efficiency are not realised because of market failures and barriers; barriers and failures that can be addressed by energy efficiency policy instruments (for specific instruments see chapter 4.3). If both emission trading and energy efficiency approaches are applied in the same market and at the same time, they interact.

ETS stimulate investments in end-use EE measures indirectly through energy prices (IEA, 2011a, Cowart, 2011). If the ETS fixed cap is reduced, the prices for allowances increase. Energy providers pass on the additional costs from the ETS and raise their prices according to their emission intensity. With higher energy prices, investments in EE measures become more attractive for end users. In comparison, policy-induced EE measures decrease the total downstream demand for energy and through this the demand for allowances. When an emissions cap is in place, lower electricity demand compared to a reference case will lead to lower emission allowance prices and thus lower electricity prices, as long as there is no policy intervention. However, when electricity demand is reduced, policy makers may decide to tighten the emission cap in a way that keeps emission allowance prices at the same level they would be without the electricity demand reduction.

The European electricity market is an area within which the European ETS (EU-ETS) and EE-instruments interact. In the EU-ETS, the electricity generating sector and energy intensive industries are obliged to submit allowances for their emissions, and the amount of allowances for each trading period is fixed in advance. For the current phase of the EU-ETS, phase III (2013 - 2020), the number of allowances was announced in 2009 (EC 2009). When 
determining this target, future policy measures for energy efficiency improvements beyond business-as-usual were not considered. Also, the impact of demand reduction due to the economic crisis has not been taken into account. Since then, measures such as the Energy Efficiency Directive (EED) 1 have suggested reducing the demand for electricity by addressing market failures and barriers to EE (EC 2011a). The European Commission (EC) has recognised the possible downward pressure of the EED on the carbon price (EC, 2011e, 2011f).

The aim of this article is to understand the impact of demand reduction in the electricity sector due to energy efficiency measures while the emission cap is fixed. The present work establishes a theoretical framework for such interactions and assesses them quantitatively with a supply-side electricity market simulation model.

Two basic research questions will be discussed in this paper: 1) What is the effect of EE policy instruments that reduce electricity demand on the EU-ETS, i.e. on the prices of European emission allowances (EUA, right for emitting 1t of CO2)? And 2) What is the resulting overall cost effect on electricity customers, especially the EU industries, as a result of introducing EE policy instruments?

The article is structured as follows: Section 2 provides a literature review of research on such interaction effects. Section 3 briefly describes the applied methodology. Subsequently, the EU-ETS and instruments of European EE policy are outlined, and the resulting impacts of their combination on carbon prices, net electricity prices and emission levels are assessed theoretically in section 4 . Section 5 presents our modelling approach: the electricity market simulation model and cost calculations. The results are presented and discussed in section 6 ; they include the estimations of electricity and carbon prices and the overall cost impact on the European industry sector due to the EU-ETS prior to and after the introduction of EE policies. Section 7 concludes.

\section{Literature review}

A variety of research studies deal with interactions between policy instruments. Interactions between climate and energy policy are discussed for example in Oikonomou \& Jepma (2007), Oikonomou et al. (2010), Sorrell \& Sijm (2003), Sorrell (2003), Konidari \& Mavrakis (2006), Lehmann (2012), Lehmann \& Gawel (2012), Böhringer et al. (2009), De Jonghe et al. (2009), del Rio (2007), Matthes (2010) and Rathmann (2007). A common research finding is that energy and climate policy interactions can have either positive or negative effects on achieving a specific emission target (Oikonomou et al., 2010). Therefore, several papers such as Fischer (2008) and Goulder \& Mathai (2000) attempt to determine the mix of policy instruments optimal to achieving a specific emission target at the lowest cost. Recent articles that focus on the combination of end-use EE policy measures and the EU-ETS have been published by Sorrell et al. (2009), and IEA (2011a). Sorrell et al. (2009) show that parallel implementation of an electricity-focused white certificate scheme (tradable saving obligations scheme) and cap-and-trade scheme will not reduce GHG emissions unless the ETS cap is tightened as a result of the introduction of the white certificate scheme. The main finding of IEA (2011a) is that carbon pricing is a prerequisite for least-cost carbon reduction strategies, but that carbon pricing alone will not address all barriers in end-use EE. Further, IEA (2011a) concludes that, in addition to carbon pricing, other policies are necessary to overcome the barriers in end-use EE, and identifies several EE policies that are complementary to carbon pricing. The possible downward effects of EE improvements on the carbon price are not quantified in the study.

The EU impact assessment for the EED (EC, 2011e, 2011f) estimates the quantitative effects of different EE policy options on the price of EUAs. The modelling results obtained with the econometric E3ME model suggest that the introduction of EE policies may significantly reduce the price in the EU-ETS - possibly down to zero, depending on the

\footnotetext{
${ }^{1}$ The EED includes binding measures and targets for EU Member States to increase energy efficiency such as the establishment of energy efficiency obligation schemes or public EE procurement, smart meter rollouts after positive evaluation etc. The EED is presented in more detail in section 4.3.
} 
implemented policy options (EC, 2011e, 2011f). This result illustrates the possible severity of EE-ETS interaction effects. A study that provides further insights into the current fear of collapsing carbon prices in the EU-ETS has recently been published by Climate Strategies: they conclude that the prices in Phase III could range widely, from "below 5" $€ / \mathrm{tCO}_{2}$ to "above 30 " $€ / \mathrm{tCO}_{2}$ (2012, p. 35) depending, amongst other things, on future measures to strengthen the EU-ETS such as reducing EUA quantities or establishing price floors. Emphasising the need for business planning security beyond 2020, Climate Strategies (2012, p. 35-36) consequently propose a more flexible system that defines price and quantity corridors in order to secure EE investments and effectively reduce emissions.

The Öko-Institut models the effects of a 1.4 billion EUA set-aside ${ }^{2}$ and a respectively tightened cap for different EE and economic development scenarios. The authors find EUA prices in 2020 of 14 to $32 €$ in different scenarios (Öko-Institut, 2012, p. 55). Similar to Climate Strategies (2012), they conclude that fundamental shifts of baseline emissions (due to e.g. lower economic growth or EE policies) "should be reflected by a strictly rule-based and high-threshold provision to lower the cap in the ETS" (Öko-Institut, 2012, p. 66).

Increasing renewable energy supply has market effects similar to electricity savings. ${ }^{3} \mathrm{~A}$ recent study on the long-term effects of the German nuclear phase-out models scenarios for different emission caps, renewable energy development, and EE policies (DIW, 2012). The DIW projects carbon prices of between 6.5 and $19 €$ in 2020 (DIW, 2012, p. 21). The authors also criticise that feedback effects of carbon prices on the electricity market are seldom analysed (DIW, 2012).

Our paper builds on these approaches. We estimate EU-ETS and electricity prices for different emission reduction and EE targets. As an addition to previous studies on this topic, we further estimate the impact of the scenario results on the competitiveness of the European industry as electricity end-users.

\section{Methodology}

Expected effects of EE policy are illustrated in fig. 1. EE policy instruments can, in principle, target all sectors, fuel types, and electricity consumption. In this paper, we only evaluate EE policy instruments targeting electricity consumption. We analyse a reduction of the forecasted baseline electricity demand resulting from a successful implementation of $E E$ policy instruments, net of rebound effects. ${ }^{4}$

Figure 1: Cause-effect diagram

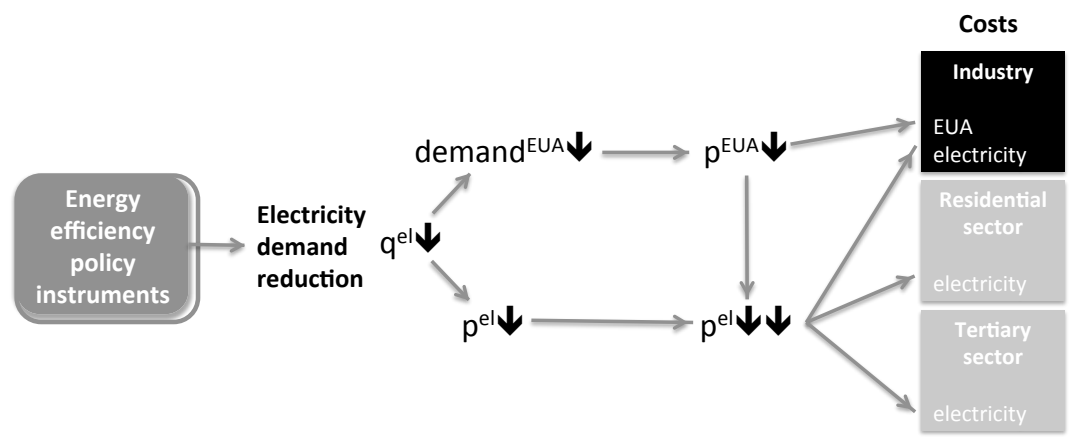

\footnotetext{
${ }^{2}$ In a „set-aside“, allowances are temporarily not offered in auctions but returned to the market at a later point in time.

${ }^{3}$ Preferential dispatching of renewable energy in the electricity market leads to a "merit-order effect", crowding out the most costly marginal power plants (Sensfuß et al, 2008; see fig. 2 A). A demand reduction of the same quantity cuts off the same power plants from the marginal generation cost curve. Note: the price effect will still be different due to cost apportionments.

${ }^{4}$ One important limit to effective EE policies is the "rebound effect" (see for example Greening et al., 2000, Breakthrough Institute, 2011). More efficient technologies often lead to increased usage of the technology (direct rebound), to energy-using spending of the saved energy expenses (indirect rebound) or higher economy-wide energy use due to lower energy prices (macroeconomic rebound). This may partially (or even wholly) reduce the overall savings.
} 
The objective of this study is to evaluate the market price effects of reduced electricity demand and the resulting effect on overall industrial competitiveness (black box in fig. 1), because this has been a central argument for higher/lower emission targets. This study does not evaluate individual costs and benefits resulting from investments in EE measures. Nevertheless, our conclusions on industrial competitiveness are valid if one of the following assumptions holds: 1) Industry invests in $E E$ and measures are cost-effective (i.e. the savings exceed the costs); or 2) EE investments (and savings) are made in sectors other than industry, leading to electricity and carbon price effects that as well improve industrial competitiveness. The first assumption is plausible, since well-designed EE policies focus on the cost-effective savings potentials and there are large cost-effective EE potentials not realised due to market failures and barriers (McKinsey 2009, Wuppertal Institut 2010, IEA 2010). The second assumption is plausible for many electricity saving policies that focus on non-industrial sectors, for example most EED or EU-Ecodesign Directive policy measures. For EE policies that meet these assumptions, our results are valid estimates. This approach is necessary in order to isolate the market price effect.

Our methodological approach follows the research questions from section 1. We answer the first question (electricity demand effect on carbon and electricity prices) by simulating the EU electricity market for different electricity demand reduction and carbon cap scenarios, and use the results to answer the second question on cost effects on industrial end-consumers.

\section{Energy efficiency and climate policy instruments in the EU}

\subsection{Aims of the European energy and climate policy}

Since the establishment of the Common Energy Policy, the EU has dedicated itself to three goals: sustainability, security of energy supply and competitiveness (EC 2007). The European Commission set these goals to combat climate change, limit the EU's external vulnerability to imported hydrocarbons, and promote growth and jobs, thereby providing secure and affordable energy to consumers (EC, 2007, p. 5). EU member states have defined a common energy strategy 2011-2020 (EC, 2010a) with the so-called "20-20-20" targets. These targets include for the year 2020 primary energy savings of $20 \%$ relative to what was projected by a business as usual scenario from 2007 , , a $20 \%$ share of renewable energies in EU final energy consumption and a $20 \%$ reduction in GHG emissions compared to the reference year 1990 .

\subsection{The EU-ETS}

The EU-ETS is the cornerstone to achieve the above emission target. The EU-ETS covered sectors (all electricity producing plants with an installed capacity of more than $20 \mathrm{MW}$, and a large share of the energy intensive industries) are to reduce their combined emissions compared to the year 2005 by $21 \%$ until 2020 . The Council offered to tighten the overall GHG emission target to $30 \%$ until 2020 , if a binding international treaty for "comparable emission reductions" is signed (Council of the European Union, 2007, p. 12). The preamble to the climate policy target shows the will to reduce GHG emissions significantly without losing competitiveness of and attractiveness to companies acting on global markets. This is one often stated conflict between the long-term goals of sustainable climate protection on the one hand and competitiveness of European industries through appealing energy prices on the other (EC, 2010a).

Market-based cap-and-trade schemes such as the EU-ETS provide participating actors with incentives to reduce emissions to the point where the marginal costs of abatement equal the price of the certificates. In static terms, and in a theoretically perfect world, certificate trading would lead to an efficient allocation of emissions. In a market with rational actors, the emissions would therefore be reduced at minimum cost. In economic theory, the emission reduction target is usually assumed to be exogenous. In practice, however, the cap is set conditional on the costs to industry (based on expected carbon prices), in order to maintain competitiveness. The internalisation of external GHG emission costs through the ETS puts 
additional costs on obliged companies, at least if emission rights are being auctioned (polluter-pays principle). Companies that are subject to international competition will therefore lose competitiveness, at least to a certain extent (unless the ETS drives them to implement cost-effective measures whose energy cost savings outweigh carbon costs). Additional costs provide an incentive to relocate parts of, or even the whole production process to regions without obligations to pay for emissions. This increases emission levels in those regions, an effect referred to as 'carbon leakage' in the literature (Mustafa, 2005).

Companies covered by the EU-ETS are obliged to submit certificates for their emitted $\mathrm{CO}_{2}$ (European Parliament and Council, 2003). Emissions from the transport, residential, public, and commercial sectors are not considered in the scheme. In 2009 , about $40 \%$ of total European GHG emissions ${ }^{5}$ were covered by the EU-ETS. By adding the aviation and other industrial sectors to the scheme, it covers approximately 45\% of the gases by 2013 (EC, 2013). For these emissions, the EU-ETS defines a fixed cap (EC, 2013). In the current trading period (2013-2020), the cap is reduced by $1.74 \%$ every year amounting to $21 \%$ GHG reductions in 2020 (relative to 2005). The 2012 annual cap of 2.08 billion tons of $\mathrm{CO}_{2}$ per year will be reduced to 1.72 billion tons of $\mathrm{CO}_{2}$ in 2020 (EC, 2009).

Changes in the political framework conditions that will or may occur ex-post were not considered when setting the cap. The inelastic supply of certificates does not take into account the results or implementation of other policy instruments (or changing economic circumstances such as the financial crisis). Additional instruments reducing electricity demand or GHG emissions of the covered sectors only decrease the price of emission certificates; overall emissions remain unaffected, as long as carbon prices remain above zero (Sijm, 2005). ${ }^{6}$ Finally, the dynamic incentives for companies under the EU-ETS to invest in more efficient technologies decrease with lower carbon prices (Climate Strategies 2012) and the transformation of the electricity supply sector towards a low-carbon future is deferred.

\subsection{Energy efficiency policy}

As presented in the "Roadmap for moving to a competitive low carbon economy in 2050" (EC, 2011d), EE is the most cost-effective way to reduce GHG emissions in the EU, i.e. significantly more cost-effective than other options (McKinsey 2009, Wuppertal Institute 2010, IEA 2010). ${ }^{7}$

According to several studies such as Sorrell et al. (2004), Jaffe and Stavins (1994), Schleich and Gruber (2008), Schleich (2009), and Gillingham et al. (2009), the cost-effective savings potential is not fully realised due to several market failures and barriers; examples include imperfect and asymmetric information, principal-agent problems, split incentives, and behavioural failures due to bounded rationality. The ETS does not address fully these barriers or market failures (IEA 2011a, Cowart 2011), while EE policy instruments can target them more specifically, allowing for cost-effective savings potentials to be achieved.

Beyond the $20 \%$ GHG emission reduction target, the European energy strategy also aims to reduce primary energy consumption by $20 \%$ against 2007 projections until 2020, corresponding to primary energy savings of 368 Mtoe (European Council, 2007; EC, 2011a). The purpose of this target is threefold: to dampen the expected growth of energy prices; to mitigate GHG emissions; and to improve security of supply with respect to the dependency on energy imports (EC, 2010a). ${ }^{8}$ However, the EC expects that the regulatory framework in

\footnotetext{
${ }^{5}$ GHGs other than $\mathrm{CO}_{2}$ are partially included in the ETS since 2013.

${ }^{6}$ Additional policy instruments may, however, influence the distribution of emissions and costs between individual firms operating under the EU-ETS due to pecuniary externalities.

${ }^{7}$ Nevertheless, for ambitious GHG emission reduction targets (like the EU's long-term target) more than just energy efficiency will be needed such as renewable energy supply, carbon capture and storage or reforestation.

${ }^{8}$ In $2009,53.9 \%$ of the energy consumed in the EU was imported. It increased significantly during the last ten years, especially the import share of oil (83,5\%) and natural gas $(64,2 \%)$ (Eurostat, 2011), and is expected to increase further (EC 2011d).
} 
place in 2012 will only achieve half of the $20 \%$ primary energy reduction target (EC, 2010a, 2011b).

To close this gap, the EC proposed the EED, which includes a set of EE policy measures and national targets for the member states (EC, 2011a, 2011c). The measures include rules for retrofitting public and private buildings, the implementation of EE obligation schemes for energy companies, obligations for public bodies to purchase EE products (public procurement), rules for energy audits, energy management systems, smart metering and informative billing, consumer information and empowering programmes and the promotion of the energy service market. The objective of the EED is to induce EE investments in order to achieve the cost-effective energy savings potential in the $E U$ (EC, 2011c). The EU parliament voted in favour of the EED in September 2012 and it was adopted on 25 October 2012. Member states have to submit National Energy Efficiency Plans (NEEAPs) annually (Art. 24). The directive has to be transposed into national laws, regulations and administrative provisions by EU Member States until 5 June 2014 (Art. 28), when it will replace previous directives (ESD, 2006/32/EC and 2004/8/EC).

\subsection{Interactions between electricity demand reduction policies and emission trading schemes}

EE policy instruments that reduce electricity demand indirectly lower the demand for emission allowances, ceteris paribus, and decrease the prices of both electricity and emission allowances (see figure 1). With lower demand, existing power plants with high variable costs ("peak load plants") are not used anymore or are used less often and the marginal price for generating electricity is reduced to the level of power plants with lower variable costs ("base load power plants"). This short-term effect on electricity market prices is known as "demand response induced price effect" - DRIPE (Heffner and Campbell, 2012; see fig. 2 A). ${ }^{9}$

The magnitude of the certificate demand reduction depends on the $\mathrm{CO}_{2}$-intensity of the electricity generation capacity, especially of peak load power plants. Since the cap of the EUETS is fixed, i.e. the certificate supply is inelastic, reduced certificate demand leads solely to a decreasing carbon price while the emissions remain at a constant level (see fig. 2 B; Sijm 2005, Lehmann and Gawel 2012) - unless the cap is adjusted for the achieved energy savings. Once a carbon price of zero is reached, further EE measures do reduce emissions. The lower the carbon price, the lower the economic incentives to reduce GHG emissions through investments in more efficient technologies. Lower carbon prices increase profitability of more carbon intensive energy sources - they lead to a crowding-in of more emissionintensive generation plants resulting in higher $\mathrm{CO}_{2}$ emissions per $\mathrm{MWh}$ of electricity.

All electricity consumers benefit from both the DRIPE and carbon price effects through reduced electricity prices. This is important with respect to the research question: both effects improve the economic competitiveness of the industrial sector to the extent that companies purchase electricity on the market. In addition, industrial companies that are subject to the EU-ETS - whether they purchase electricity or not - directly benefit from reduced EU-Allowance (EUA) prices through lower costs for direct purchases of certificates.

\footnotetext{
${ }^{9}$ This effect is limited to one investment cycle - if the demand is reduced for a longer period (e.g. beyond 2020), the power plant fleet will adjust, and base load power plants with low utilization are replaced by peak load power plants with lower capital costs.
} 
Figure 2: Schematic impact of electricity demand reduction on the electricity market (A) and ETS (B)
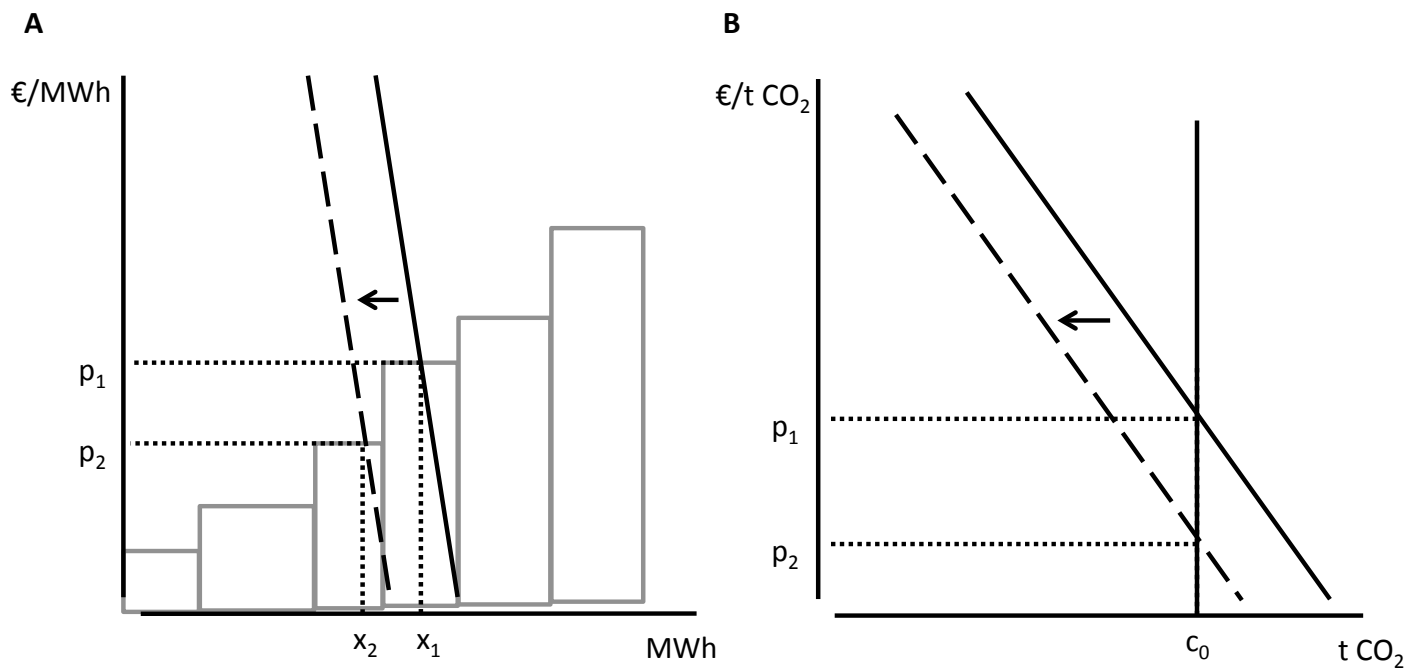

When the EC set its 2020 sub-goal of reducing the EU-ETS emission cap by $21 \%$ versus 2005 levels (EC 2009b), it considered the resulting costs to be, ex-ante, an acceptable burden for European consumers and especially for industry. In the following, we scrutinise if and to what extent the EU-ETS cap can be tightened in light of lower-than-expected electricity demand without further reducing the competitiveness of industries in the EU.

\subsection{Adjustments of policy instruments}

Policy instruments proposed within the EED lower the cost burden for companies that purchase electricity or EUAs, which results in higher competitiveness. Under the assumption that the monetary burden of companies from climate policy targets was previously considered acceptable, a commensurate adjustment of the emission targets may be considered. In order to strengthen the EU-ETS accordingly, the European Commission suggested reducing the number of certificates if the price stays below a certain benchmark or if the target of $30 \%$ emission reduction is agreed upon (EC, 2010b, 2011a). In December 2011, the European Parliament's Committee on the Environment, Public Health and Food Safety (ENVI) more specifically suggested setting aside 1.4 billion $\mathrm{CO}_{2}$ certificates (ENVI, 2011). This would mean heading for the target of reducing annual emissions by $30 \%$ and additionally cancelling overallocated EUAs from the second period that have been banked into the third period. By November 2012, the Commission proposed to "delay 900m EUAs" (ICIS 2012). However, at the end of February 2013, the ENVI postponed the discussion until March or April 2013 to take place in the EU parliament (Euractiv 2013).

Figure 3 presents the rationale for possible adjustments of the emission cap following the effects of EE policies. The aim should be to strike the right balance between tightening the cap and keeping the industrial sector competitive. In the following, we use scenario analysis to assess the possibilities for achieving such a balance. 
Figure 3: Rationale for cap adjustments

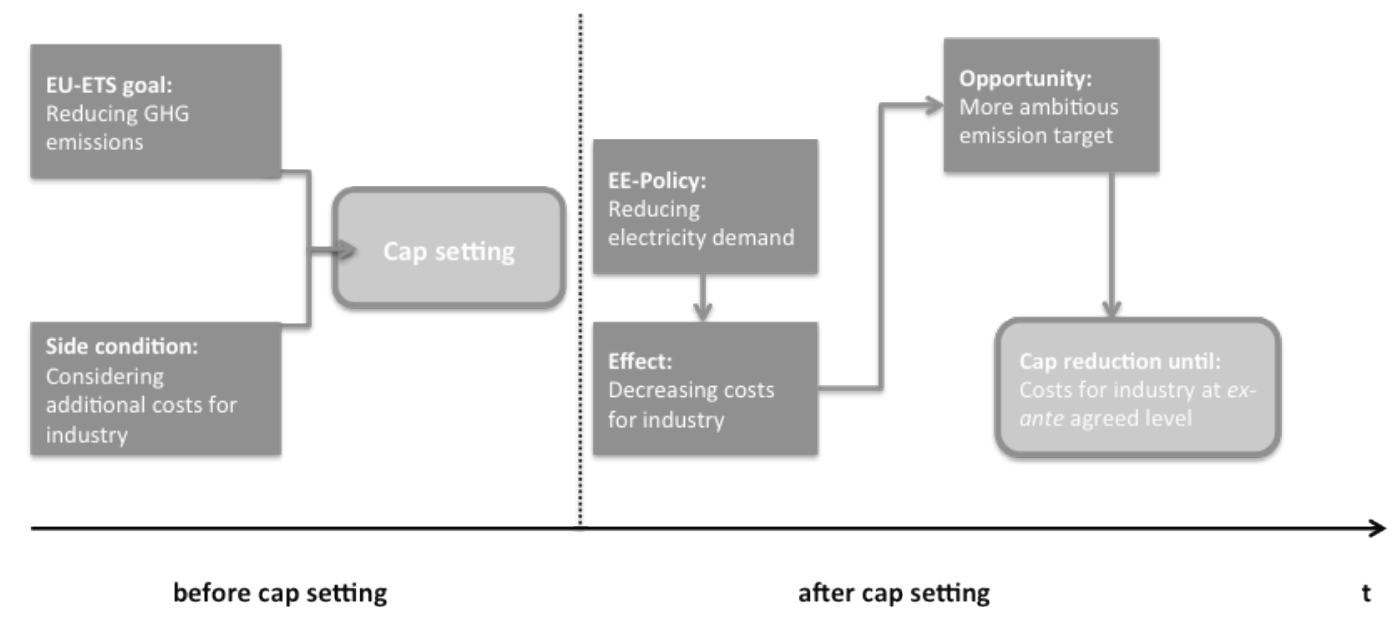

\section{Modelling energy efficiency policy effects}

We operationalise EE policy as a reduced electricity demand compared to demand in a business as usual (BAU) scenario. In order to answer our research question about the effects on industrial competitiveness, we take a two-step approach: first, we analyze the effect of EE policy on electricity and carbon prices with an electricity market simulation model. In a second step, we use the model's results to calculate the cost relief from reduced electricity and $\mathrm{CO}_{2}$ prices on European energy-intensive industries. The following sections present our model and assumptions.

\subsection{Effects on electricity and carbon prices: Modelling and assumptions}

Our electricity demand scenarios are modelled with the high-resolution electricity supply model DIMENSION of the Institute of Energy Economics EWI at Cologne University (Richter, 2011). DIMENSION is a long-term simulation model for 27 European electricity markets, essentially covering the EU (Malta and Cyprus are not considered, while Switzerland and Norway have been entered). This model is regularly employed for analyses commissioned by e.g. the German federal government or the EC, and for other studies of the European electricity markets (EWI, 2012; Prognos et al., 2011; EWI \& energynautics, 2011).

For this paper, the model has been simplified to encompass nine regions including all 27 states (see table 2 in annex). All power plants and energy storage facilities $>50 \mathrm{MW}_{\mathrm{el}}$ for these states have been entered into a database that EWI updates on an ongoing basis.

Emissions from the power sector are endogenously calculated according to the emission factors of fossil fuels and the efficiencies of power plant classes. Process emissions from the industrial sector are treated exogenously. They are assumed to decrease by a small factor $(0.5 \%)$ every year due to technical progress and are subtracted from the fixed cap before it is applied in the model only to the electricity sector.

By this approach, the marginal costs of $\mathrm{CO}_{2}$-abatement in the power sector approximate the price for EUAs. In the model, the price is determined by the $\mathrm{CO}_{2}$-emissions of one additional unit of electricity production. Prices for EUAs rise, if the marginal power plants are heavily emitting units such as coal power stations. If the additional unit is gas-fired, the increase of prices are lower. If they are $\mathrm{CO}_{2}$-neutral, the price does not change. However, feedback effects between lower electricity prices and the industry's own ETS emissions are neglected such as substitution of fossil fuels by electricity or carbon leakage.

DIMENSION operates in two steps. First, the dispatch of the power plants for typical days is estimated for each of the simulated years. The utilisation of power plants' capacity is limited by technical restrictions, mainly by the ramp up speed and load gradients. Trade is limited by interconnector capacity between the simulated regions. Assumptions about fuel prices and capacity additions are similar to Prognos et al. (2011). According to our scenarios (see below), different caps are set on the total emissions of the dispatched power plants and 
obliged industries for the period from 2013 to 2020. Resulting prices and power plant portfolios are then modelled. The simulation allows for banking, i.e. allowances can be transferred from one trading period to another, which is in line with actual EU-ETS rules. Therefore, the emissions of the electricity sector are determined by European legislation for the entire third EU-ETS period.

In the second step, DIMENSION models the future development of installed capacities and power storage facilities in Europe and resulting EUA prices and marginal generation costs. New power plants are added to the starting fleet based on the estimated extra full load hours required. When only a few extra hours of full load are required each year, investment is made in power stations with low capital and high variable cost, e.g. gas-fired power plants, while stations with lower variable costs are preferred for a high annual utilisation. DIMENSION assumes that the European markets will achieve the cost-minimising mix of different technologies, a market result that is set in full competition and perfect information. Under these assumptions and because exogenous shocks cannot be foreseen and are thus not taken into account, the modelling yields constant EUA price estimates throughout the third trading period. The modelled marginal generation costs approximate wholesale market prices net of transmission and distribution tariffs and taxes. EUA costs to the electricity generation sector are fully passed on to end-users via electricity prices. These electricity prices are determined by a large set of variables and assumptions in the simulation. Technology characteristics, fuel prices, electricity demand and carbon prices are among the important factors.

Although for this analysis developments in the current EU-ETS period only are of interest until 2020, decisions were modelled until 2040 in order to properly reflect long-term power plant investment decisions. ${ }^{10}$

\subsection{Calculating the cost impact on European industry}

As presented in section 2, within the analysis of market price effects, there are two direct channels how EE and climate policies affect industry costs: through electricity costs and costs of EUAs purchased by industry (excluding the electricity generation sector). We thus follow the simple formula of cost $=$ price $\times$ quantity $(C=p \times q)$ :

$$
C_{\text {industry }}=c_{\text {industry }}^{e l}+c_{\text {industry }}^{\text {EUA }}=p^{e l} q_{\text {industry }}^{e l}+p^{E U A} q_{\text {industry }}^{\text {EUA }}
$$

Industrial costs are calculated for the years 2012-2020. The industrial electricity consumption $q^{e l}{ }_{i t}$ with estimations until 2020 is obtained from Eurelectric (2010) for 27 EU member states, Norway, and Switzerland. Total costs are obtained by multiplying the electricity price $p^{e l}$ it provided by DIMENSION with the overall industrial consumption $q^{e l}{ }_{i t}$ (see eq. 2 ).

Figure 4: Modelling effects of EE and climate policies

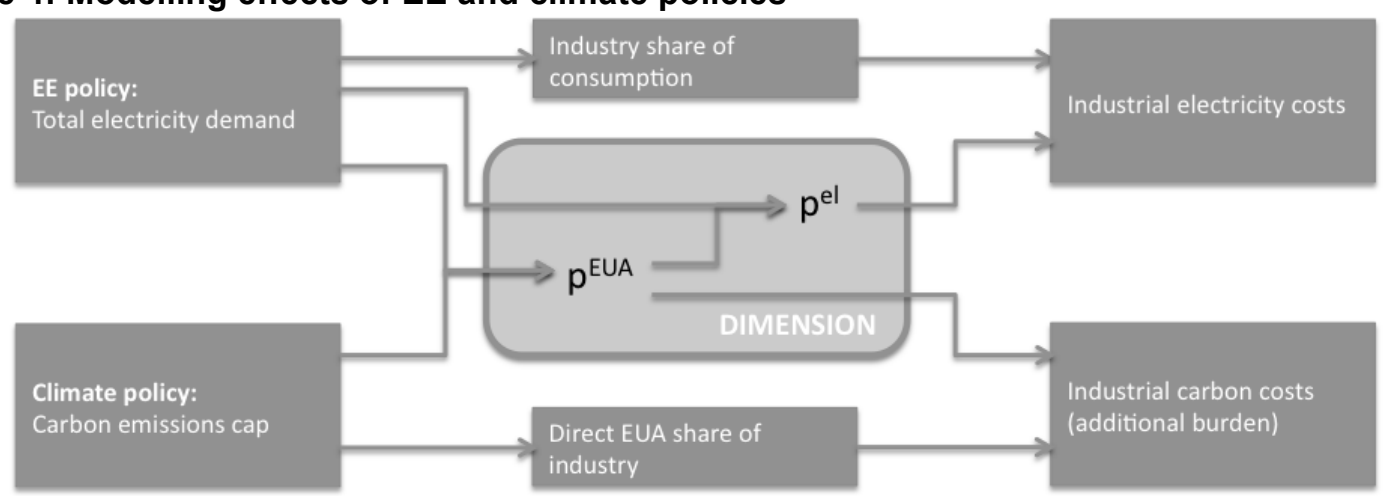

\footnotetext{
${ }^{10}$ The scenarios are designed to show the outcomes of the political target until 2020. Therefore, banking of phase III-certificates to period IV is not allowed in the model. After 2020, prices for carbon emissions have been assumed to constantly increase from $20 € / \mathrm{tCO}_{2}$ to $35 € / \mathrm{tCO}_{2}$ in 2040 .
} 
The share of EUA purchases from industry in 2010 (non-electricity generation sectors) $\beta$ is derived from statistics of EEA (2012): in 2010, 26.4\% of the verified emissions were emitted in industrial installations (EEA, 2012). Additionally, about $10 \%$ of the remaining "combustion" sector can be assigned to the industrial sector (Trotignon \& Delbosc, 2008). We therefore assume that in $2010, \beta=33.8 \%$ of the EU-ETS' emissions were caused outside of the electricity generation, but within the industrial sector. While, for the baseline scenario, total emissions decrease by $1.74 \%$ per year for a total of $21 \%$ reduction by 2020 , we assume that the number of certificates in the industrial sector decreases at a rate of $0.5 \%$ per year (from 2010 onwards) due to a lower emission reduction potential (Grave, 2010). We model total costs of industry as the sum of two products where costs are summed up for regions $i=$ $1, \ldots, n$ and years $t=2012, \ldots, 2020$ with prices $p$ and quantities $q$ being those relevant for industry:

$$
C=\sum_{i=1}^{n} \sum_{t=2012}^{2020} p_{i t}^{e l} q_{i t}^{e l}+p_{t}^{E U A} q_{t}^{E U A} \beta(1-0.005)^{t-2010}
$$

Since the model does not include frictions in information and investments, and transmission and distribution tariffs and taxes remain unconsidered, end-user electricity prices cannot be modelled accurately. It is thus not sensible to interpret the results calculated from equation 2 as end-user electricity and carbon costs. We therefore apply a difference-in-cost design: we calculate net electricity costs with no ETS in place as a baseline scenario. Assuming constant transmission and distribution tariffs and taxes, subtraction of these baseline costs from the modelled scenario costs (EUA and electricity) yields an unbiased estimation of the additional costs to industry relative to a scenario without an ETS (for results see fig. 8 and 9 , for values see table 4 in the annex).

\subsection{Scenarios}

To estimate the industries' incurred costs due to the EU-ETS, we first calculate the total costs of industries without a $\mathrm{CO}_{2}$-trading system (scenario noETS) and compare this situation with the business-as-usual (BAU) scenario of $21 \%$ cap reduction until 2020 with possible banking of EUAs remaining from the second trading period.

EE policies are modelled as a reduction in electricity demand. In recent energy scenarios for the EU, electricity demand is expected to decrease by $5-7 \%$ compared to BAU due to EE (for figures see annex; EC, 2011g; IEA, 2012; EREC \& Greenpeace, 2012; Eurelectric, 2009). Information about the expected effects of the EED on electricity demand is scarcely available. ${ }^{11}$ We expect, that national implementations of EED policy measures show effects from 2015 on. ${ }^{12}$ Introducing ambitious EE policies and combining it with optimistic technological EE development scenarios may lead to an electricity demand reduction in the range of up to $2 \%$ annually, amounting to a decrease in electricity demand of up to $10 \%$ until 2020. From the literature and above estimations we therefore derive two exemplary scenarios: a lower EE scenario with $5 \%$ and an optimistic EE scenario with $10 \%$ electricity demand reduction relative to the BAU scenario. We estimate the effect of these two demand reduction scenarios on electricity prices and on the marginal costs for emission allowances for each of three emission cap scenarios (see table 1): 1) A cap as currently defined $(-21 \%$ compared to the allocation of 2005), 2) setting aside certificates which have been

\footnotetext{
${ }^{11}$ The EED impact assessment includes quantitative estimates of the effects on primary energy consumption, but not on electricity consumption (EC 2011e, 2011f). Calculation of electricity savings from primary energy savings estimated for the EED scenarios in the impact assessment as preferred by the EC was not possible, as critical assumptions and intermediate steps were not available to us.

${ }^{12}$ The EED will not be translated into national legislation before 2013. Consequently, our results are displayed from 2013 until the end of the third trading period of the EU-ETS in 2020.
} 
overallocated and remained in phase II, mainly because of the economic crisis that reduced the demand for EUAs and that were banked to period III; they are modelled as a $355 \mathrm{Mt}$ reduction of EUAs ("-355Mt") and 3) scenarios with a total set aside of $1400 \mathrm{Mt}$ ("-1400Mt") as proposed by ENVI (2011). This corresponds to a set-aside of $1045 \mathrm{Mt}$ (equivalent to a $30 \%$ emission reduction) plus a set-aside of remaining phase II certificates (355 Mt).

\begin{tabular}{lccc} 
Table 1: Scenario assumptions & $\begin{array}{c}\text { Electricity demand } \\
\text { decrease rel. to BAU } \\
\text { Scenario }\end{array}$ & $\begin{array}{c}\text { Set aside compared } \\
\text { to current legislation } \\
\text { (Mt) }\end{array}$ & $\begin{array}{c}\text { Equivalent to a cap } \\
\text { reduction relative to } \\
\mathbf{2 0 0 5}(\%)\end{array}$ \\
\hline noETS & - & - & - \\
BAU & - & - & 21 \\
EE5\% & 5 & - & 21 \\
BAU -355Mt & - & 355 & $21(-355 \mathrm{Mt})$ \\
EE5\% -355Mt & 5 & 355 & $21(-355 \mathrm{Mt})$ \\
EE10\% -355Mt & 10 & 355 & $21(-355 \mathrm{Mt})$ \\
BAU -1400Mt & - & $1045+355$ & $30(-355 \mathrm{Mt})$ \\
EE5\% -1400Mt & - & $1045+355$ & $30(-355 \mathrm{Mt})$ \\
EE10\% -1400Mt & 5 & $1045+355$ & $30(-355 \mathrm{Mt})$ \\
\hline
\end{tabular}

Because the revision of the EU-ETS Directive is not a probable near-time policy, adjustment of the cap e.g. to a $30 \%$ cap reduction is not realistic. However, as the EU-parliament's Committee on the Environment (ENVI, 2011) proposed, setting aside the respective EUA quantities for phase III might be an option, which we model (and term) as a cap reduction.

As our model allows intra-period-banking until 2020 and calculates optimal decisions, EUA prices are constant for the whole trading period, reflecting a given supply and demand of overall third-period EUA quantities.

\section{Results}

\subsection{Electricity and carbon prices}

The estimated prices show the expected tendencies: tighter EU-ETS caps lead to higher EUA and electricity prices, while more EE leads to the opposite. In the BAU scenario, the EU-ETS is characterized by a $21 \%$ emission reduction target in 2020 and the carbon cap is accordingly adjusted by $1.74 \%$ per year. No additional electricity demand reductions are modelled in this scenario. If remaining EUAs from period-II (2005-2012) are banked to period III (2013-2020) and nothing is set aside, our projected EUA price collapses to 0 . This is the consequence of emissions being lower than the cap (certificate oversupply). Climate Strategies also argues that real residual "emissions [are] already below [the] cap so prices could be low" (2012, p.16). If the $355 \mathrm{Mt}$ remaining from phase II are set aside from period III-quantities, we project a price of $12 €$, falling to 0 if EE policy reduces electricity demand by $5 \%$. If, additional to the $355 \mathrm{Mt}$, further $1045 \mathrm{Mt}$ were set aside as proposed (equivalent to a GHG reduction target of more than $30 \%$ ), EUA prices would rise: our model projects $24 €$; Climate Strategies (2012) estimated EUA prices around 20€. But again, if EE policy instruments reduce electricity demand by $5 \%$ or $10 \%$ relative to BAU, EUA prices are reduced to $19 €$ or remain close to the level of a BAU scenario with set-asides $(11 €)$, respectively. ${ }^{13}$

\footnotetext{
${ }^{13}$ Recent estimates of EUA prices can also be found in Öko-Institut (2012), European Commission (2012), Climate Strategies (2012), Deutsche Bank (2011) and UBS (2011).
} 
Figure 5: Estimated EUA prices $(€ / \mathrm{tCO})_{2}$

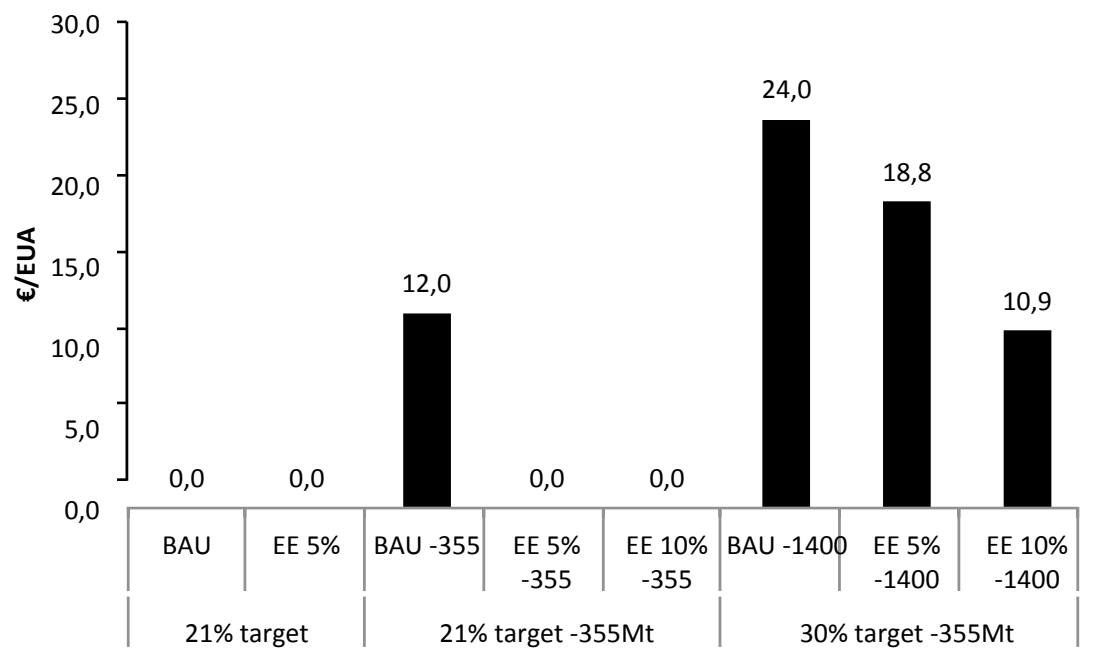

For most industry branches, electricity prices are of higher importance than carbon prices. Net electricity prices show the expected behaviour (figure 6). In the oversupply BAU scenario, the EUA-price is 0 , and electricity prices are thus lower than in scenarios where carbon costs are passed on to the customers. With stricter caps, EUA and consequently electricity prices continuously rise. Decreasing demand through EE policy brings them down again: they are lowest in the $10 \% \mathrm{EE} / 21 \%$ cap scenario. Interestingly, even with a $30 \%$ cap reduction (and $10 \% \mathrm{EE}$ ), electricity prices are only slightly higher than in the BAU scenario.

Figure 6: Average net electricity prices ( $€ / \mathrm{MWh})$

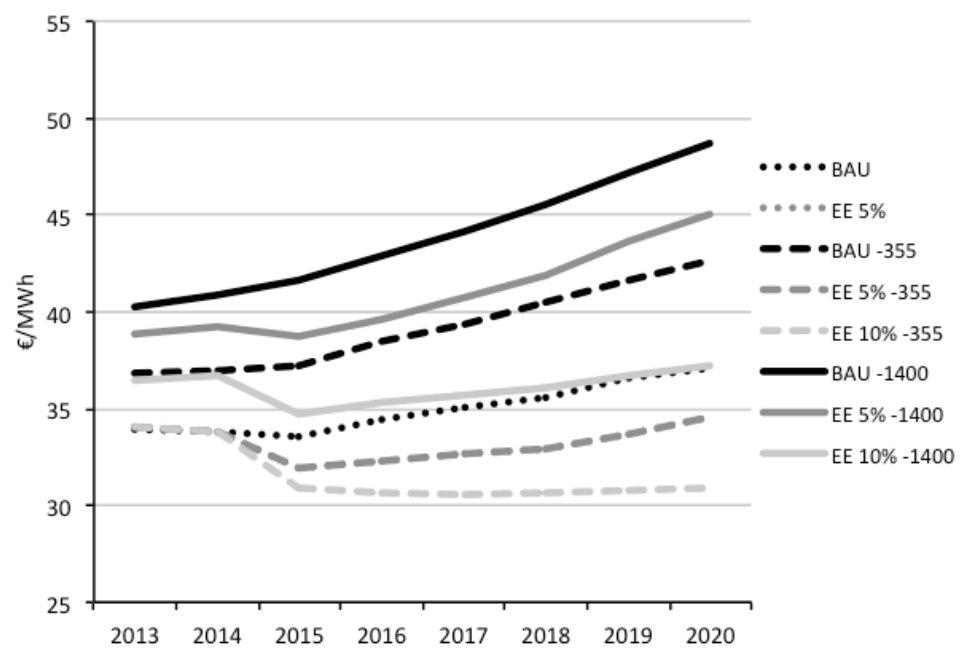

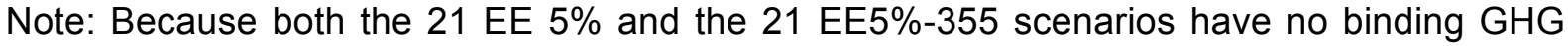
cap (oversupply), outcomes are almost identical and cannot be distinguished in figures 6-8.

\subsection{Total and additional cost impact on EU industry}

In this section, we sum the costs incurred by European industry for EUA purchases (for certificates used directly for process emissions) and electricity consumption. Figure 7 plots both cost elements in total bn € per year. 
Figure 7: Total EUA (A) and net electricity costs $(B)$ (bn $€$ per year)
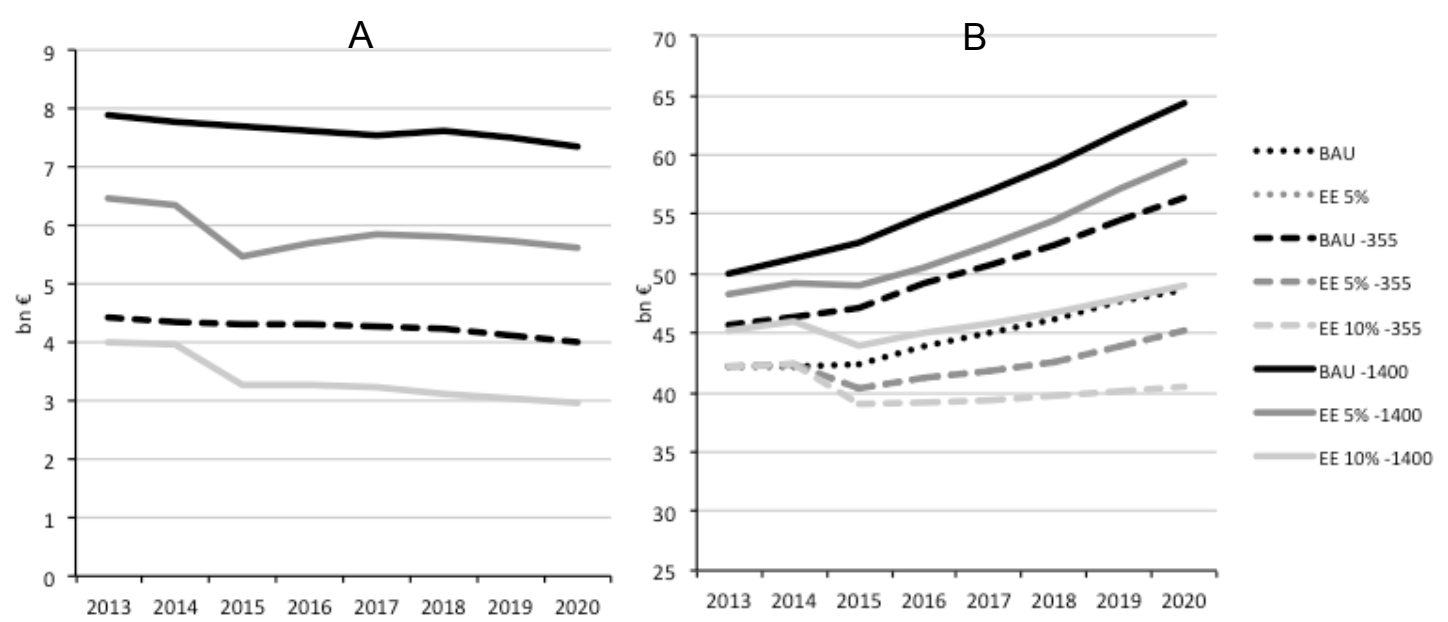

Note: For the scenarios not depicted in the EUA cost graph, costs are zero.

As expected, the introduction of EE policies reduces the costs of each BAU scenario. The more effective these policies are, the lower the costs. If the emission cap is not tightened, increased efficiency leads only to lower EUA and electricity prices, improving competitiveness. From an ecological perspective, however, the reduced emissions in the electricity sector have no effect. Indeed, the carbon intensity of electricity generation (Mt CO2/MWh) even rises.14 While annual net electricity costs range from 39 to 64 bn $€$, annual expenses for EUAs are between zero - for the scenarios with EUA oversupply - and around 8 bn $€$ maximum in a $30 \%$ GHG cap reduction scenario without any EE policy.

In the following, we compare the cost effects on EU industry to a situation in which no EUETS is in place. Figure 8 shows that, with a set-aside (-355-scenarios), $21 \%$ cap, and EE policy, industry costs are reduced to a level below a situation without an ETS and without EE policy.

Figure 8: Additional cost impact on EU industry compared to no ETS in place (per year)

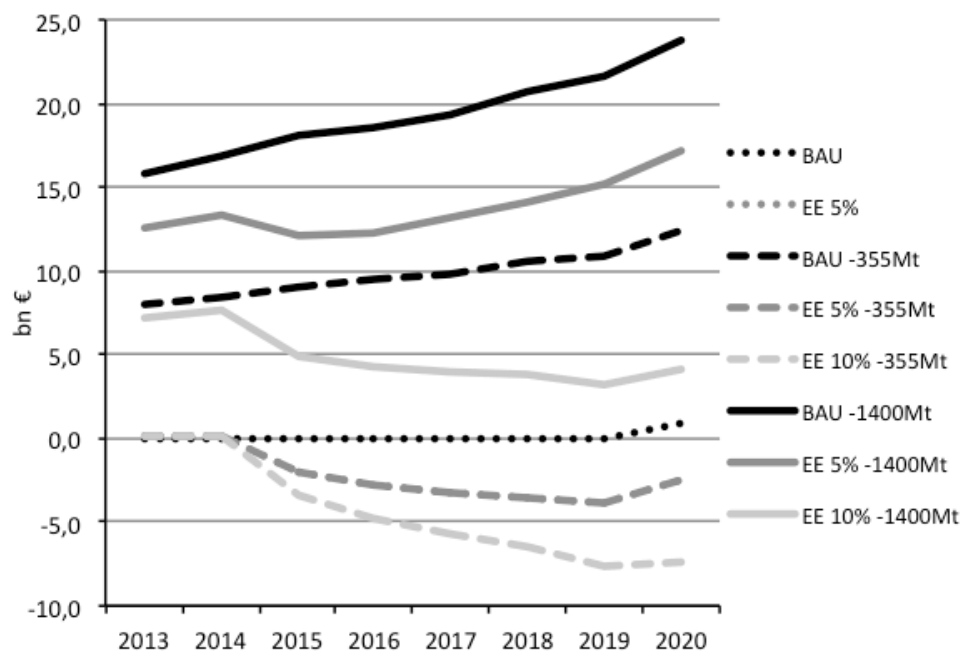

\footnotetext{
${ }^{14}$ We operationalised carbon intensity of electricity generation as the relation of Mt CO2-equivalents to TWh electricity consumption. Calculations for our $30 \%$ cap reduction scenario showed, that carbon intensity of the trading period III rises from 0,28 in the BAU electricity demand scenario to 0,29 when demand is reduced by $5 \%$ relative to BAU and to 0,3 with a $10 \%$-reduction.
} 
Maintaining acceptable electricity prices for end-users and industrial competitiveness was an important political argument when the emission cap was agreed-on with the industrial stakeholders. Therefore, we use these ex-ante agreed-on costs as a comparison reference in the following. In the Impact Assessment for the EU-ETS, the European Commission (EC 2008) expected EUA prices between 30 and $35 €$, resulting in additional costs for industry of 86-100 bn $€$ (compared to no EU-ETS, see grey bar in fig. 9). Figure 9 depicts these additional costs for all scenarios compared to a situation without a EU-ETS, accumulated over the years 2013-2020.

Figure 9: Additional cost impact on EU industry compared to no ETS in place (cumulative)

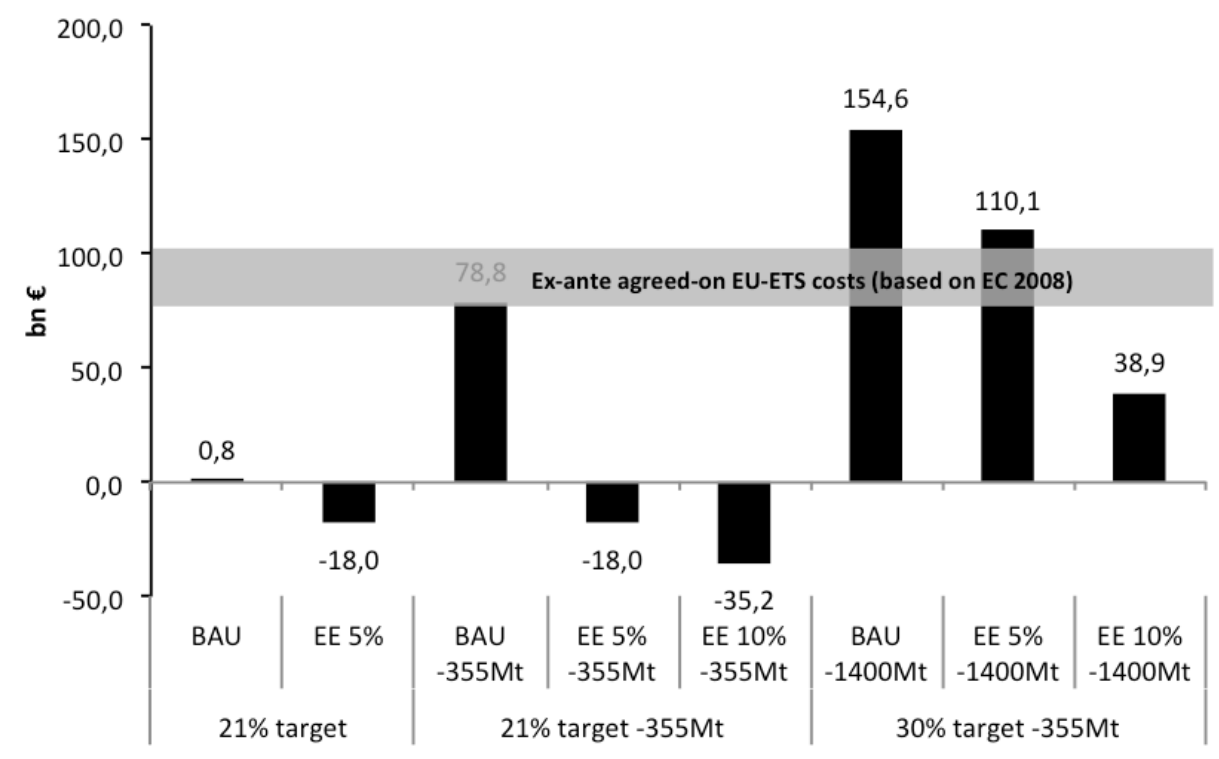

Irrespective of the chosen cap, EE policy reduces costs for industry through decreased EUA prices and lower electricity prices (DRIPE effect and less EUA-price pass-through). The more effective the policy, the higher the cost reductions for the industrial sector. As a result, the competitiveness of EU industry on world markets increases relative to a scenario without EE policy.

Model simulations and calculations yield accumulated EU-ETS-induced costs to industry (2013-2020) between -35 and 155 bn $€$. Total costs are highest (155 bn $€$ ) in a $30 \%$ GHG reduction scenario without any EE policy. Under the assumption of $5 \%$ energy efficiency savings, costs to industry are reduced to $110 \mathrm{bn} €$, and to $39 \mathrm{bn} €$ if EE policy reduces demand by $10 \%$, only slightly above or far below the ex-ante expected $86-100$ bn $€$ (grey bar).

According to our calculations, the climate target can thus be further increased and emission limits tightened without compromising the economic competitiveness of European industry above levels originally deemed acceptable.

\section{Conclusion}

This analysis estimates the effects of EE policy (operationalised as electricity demand decreases) on EUA and electricity prices with a comprehensive supply-side electricity generation model. Model results have been used to estimate the cost impact on European industry for eight scenarios: a reference scenario with no EU-ETS in place, a BAU scenario with the EU-ETS aiming at $21 \%$ emission reductions, a BAU scenario setting aside the estimated 355 Mt EUAs remaining from the second trading period and setting aside additional $1045 \mathrm{Mt}$ EUAs, which is equal to a $30 \%$ cap reduction in 2020, and several combinations of the $21 \%$ and $30 \%$ cap-reduction scenarios with an EE-induced decrease in electricity demand of $5 \%$ and $10 \%$ respectively. 
Estimations and calculations show that EE policy decreases total industrial costs through 1) lower EUA purchasing costs and 2) lower electricity market prices due to the direct demand effect and lower EUA price pass-through. The more effectively a policy reduces electricity demand, the higher the cost relief to industry. Results additionally demonstrate that if $\mathrm{EE}$ policy is not accompanied by reductions of emission certificates in an ETS setting, emissions are not reduced in the ETS-covered sectors unless EUA prices already are zero. The overall finding is that, accompanied by effective EE policy, a $30 \%$ reduction of emissions can be achieved with similar or even lower costs to industry and other end-users than expected when setting the emission cap for phase III, maintaining industrial competitiveness at agreedon levels. Our analysis concludes that ambitious emission targets are necessary if the EUETS is to persist as an effective climate policy instrument alongside EE policies, because otherwise carbon prices will fall and the EU-ETS will become irrelevant.

\section{Acknowledgements}

We are grateful for the very helpful and detailed comments of two anonymous referees which greatly improved the paper. We thank our colleagues Stefan Thomas, Wolfgang Sterk, Florin Vondung and Dorothea Hauptstock (Wuppertal Institute) for very helpful suggestions, Stefan Lorenczik (Institute for Energy Economics) for his modelling advice and Martin Jones for proofreading. Helpful comments to an early conference version were also provided by IEPEC 2012 participants.

\section{References}

Böhringer, C., Löschel, A., Moslener, U., \& Rutherford, T. F., 2009. EU climate policy up to 2020: An economic impact assessment. Energy Economics, 31, p. 295-S305.

Breakthrough Institute, 2011. Energy Emergence. Rebound \& Backfire as Emergent Phenomena. A Review of the Literature.

Climate Strategies, 2012. Strengthening the EU-ETS. Creating a stable platform for EU energy investment. Full Report.

Council of the Euopean Union, 2007. Presidency Conclusions 7224/1/07 REV 1, Brussels, 2007.

Cowart, R. 2011. Prices and Policies: Carbon Caps and Efficiency Programmes for Europe's Low-Carbon Future in: Proceedings of the eceee summer study 2011.

Deutsche Bank, 2011. Carbon update: what is the value of a political option?

De Jonghe, C., Delarue, E., Belmans, R., D'haeseleer, W., 2009. Interactions between measures for the support of electricity from renewable energy sources and CO2 mitigation. Energy Policy 37, 4743-4752.

del Rio, P., 2007. The interaction between emissions trading and renewable electricity support schemes. an overview of the literature. Mitigation and Adaptation Strategies for Global Change 12, 1363-1390.

DIW, 2012. Die Auswirkungen des Atomausstiegs in Deutschland auf Strompreise und Klimaschutz in Deutschland und Europa. Studie im Auftrag von Greenpeace e.V., Berlin.

EC - European Commission, 2007. An Energy Policy For Europe - COM(2007) 1, Brussels.

EC - European Commission, 2008. Commission Staff Working Document. Impact Assessment. Document accompanying the Package of Implementation measures for the EU's objectives on climate change and renewable energy for 2020.

EC - European Commission, 2009a. Decision No 406/2009/EC of the European Parliament and of the Council of 23 April 2009.

EC - European Commission, 2009b. Directive 2009/29/EC of the European Parliament and of the Council of 23 April 2009.

EC - European Commission, 2010a. Energy 2020 - A strategy for competitive, sustainable and secure energy - COM (2010) 639, Brussels. 
EC - European Commission, 2010b. Analysis of options to move beyond $20 \%$ greenhouse gas emission reductions and assessing the risk of carbon leakage - $\operatorname{COM(2010)~265,~}$ Brussels, 2010.

EC - European Commission, 2011a. Directive on energy efficiency and repealing Directives 2004/8/EC and 2006/32/EC - COM(2011) 370, Brussels.

EC - European Commission, 2011b. Energy Efficiency Plan 2011 - COM(2011) 109, Brussels, 2011.

EC - European Commission, 2011c. Executive Summary of the Impact Assessment SEC/2011/780, Brussels.

EC - European Commission, 2011d. A roadmap for moving to a competitive low carbon economy in 2050 - COM(2011) 112, Brussels.

EC - European Commission, 2011e. Commission Staff Working Paper. Impact Assessment Accompanying the document Directive of the European Parliament and of the Council on energy efficiency and amending and subsequently repealing Directives 2004/8/EC and 2006/32/EC, Brussels.

EC - European Commission, 2011f. Commission Staff Working Paper. Annex to the Impact Assessment Accompanying the document Directive of the European Parliament and of the Council on energy efficiency and amending and subsequently repealing Directives 2004/8/EC and 2006/32/EC, Brussels.

EC - European Commission, 2011g. A roadmap for moving to a competitive low carbon economy in 2050 - COM(2011) 112, Brussels. Annex part II.

EC - European Commission, 2012. Commission Staff Working Paper. Analysis of options beyond 20\% GHG emission reductions: Member State results.

EC - European Commission, 2013. The EU emissions trading system (ETS). Factsheet. http://ec.europa.eu/clima/publications/docs/factsheet_ets_2013_en.pdf

EEA - European Environment Agency, 2012. EU Emissions Trading System (ETS) data viewer, 2012, http://www.eea.europa.eu/data-and-maps/data/data-viewers/emissionstrading-viewer.

Endres, A., 2007. Umweltökonomie. Stuttgart: Kohlhammer.

ENVI - Committee on the Environment, Public Health and Food Safety, 2011. Environment Committee calls for ETS credits to be set aside, http://www.europarl.europa.eu/news/en/pressroom/content/20111220IPR34698/html/ Environment-Committee-calls-for-ETS-credits-to-be-set-aside

Euractiv, 2013. Carbon market intrigue after European Parliament vote cancelled. http://www.euractiv.com/climate-environment/carbon-market-intrigue-european-news518056.

Eurelectric, 2010. Power Statistics. 2010 Edidtion. Full Report. Brussels, Belgium.

Eurelectric, 2011. European Energy at a Decisive Crossroads. Statement addressed to Heads of State and Government, Brussels.

Eurostat, 2007. Energy, transport and environment indicators: 2011 edition, Luxembourg.

Eurostat, 2012. Strompreise für industrielle Verbraucher. http://epp.eurostat.ec.europa.eu/tgm/graph.do?tab=graph\&plugin=1\&pcode=ten0011 $4 \&$ language $=$ de \&toolbox $=$ data.

EWI \& energynautics, 2011. Roadmap 2050 - a closer look. Cost-efficient RES-E penetration and the role of grid extensions. Final Report.

EWI, 2012. Untersuchungen zu einem zukunftsfähigen Strommarktdesign. Endbericht. BMWi.

EREC \& Greenpeace, 2012. Energy [r]evolution. A sustainable EU 27 energy outlook.

Eurelectric, 2009. Power Choices. Pathways to Carbon-Neutral Electricity in Europe by 2050. Full Report.

Fischer, C., 2008. Emissions pricing, spillovers, and public investment in environmentally friendly technologies, in: Energy Economics, 30(2): 487-502.

Fritsch, M., 2011. Marktversagen und Wirtschaftspolitik. München: Vahlen.

Gillingham, K., Newell, R.G. \& Palmer, K., 2009. Energy Efficiency Economics and Policy. Discussion Paper 9-13. Resources For the Future. 
Goulder, L. \& Mathai, K., 2000. Optimal CO2 abatement in the presence of induced technological change, Journal of Environmental Economics and Management, 39, 138.

Grave, K., 2010. CO2-Abatement Costs in Energy intensive industries. In: Sauer, P., Sauerova, J. (eds): Environmental Economics and Management, Prague..

Greening, L. A., Greene, D. L., \& Difiglio, C., 2000. Energy efficiency and consumption the rebound effect - a survey, Energy Policy, vol. 28, p. 389-401.

Heffner, G. \& Campbell, N. 2012. Evaluating Energy Efficiency Benefits for Energy Providers and Customers. Paper prepared for IEPEC 2012, Rome.

ICIS, 2012. European Commission proposes to delay $900 \mathrm{~m}$ EUAs. http://www.icis.com/heren/articles/2012/11/13/9613712/european-commissionproposes-to-delay-900m-euas.html\#.

IEA, 2010. Energy technology perspectives.

IEA, 2011a. Energy efficiency and carbon pricing, information paper, Paris.

IEA, 2012. World Energy Outlook 2012. Paris: IEA.

Jaffe, A.B. \& Stavins, R.N., 1994. The energy-efficiency gap: what does it mean? Energy Policy 22, 804-810.

Konidari, P. \& Mavrakis, D., 2006. A multi-criteriae valuation method for climate change mitigation policy instruments, Energy Policy, vol. 35 (12), 14.

Lehmann, P. (2012). Justifying a Policy Mix for Pollution Control: A Review of economic Literature. Journal of Economic Surveys, vol. 26 (1), p. 71-97.

Lehmann, P., \& Gawel, E., 2012. Why should support schemes for renewable electricity complement the EU emissions trading scheme? Energy Policy. doi:10.1016/j.enpol.2012.10.018

Matthes, F.C., 2010. Greenhouse Gas Emissions Trading and Complementary Policies. Developing a Smart Mix for Ambitious Climate Policies. Öko-Institut e.V, Berlin.

McKinsey \& Company, 2009. Pathways to a low-carbon economy, Version 2 of the global greenhouse gas abatement cost curve. McKinsey \& Company.

Mustafa, H. B., 2005. Climate change policy, market structure, and carbon leakage, Journal of International Economics, vol. 65 (2), 421-445.

Neslen, A., 2011. Brussels slaps opt-outs on efficiency plan, EurActiv, 15.08.2011, http://www.euractiv.com/en/energy-efficiency/brussels-slaps-opt-outs-efficiency-plannews-505877.

Oikonomou, V. \& Jepma, C. J., 2007. A framework on interactions of climate and energy policy instruments, Mitigation and Adaptation Strategies for Global Change, vol. 13 (2), 131-156.

Oikonomou, V., Flamos, A. \& Grafakos, S., 2010. Is blending of energy and climate policy instruments always desirable?, Energy Policy, vol. 38 (8), 4186-4195.

Öko-Institut, 2012. Strengthening the European Union Emission Trading Scheme and raising climate ambition. Öko-Institut, WWF and Greenpeace.

Perman, R., Ma, Y., McGilvray, J. \& Common, M.. 2011. Natural Resource and Environmental Economics. Essex: Pearson.

Prognos, EWI \& GWS, 2011. Energieszenarien 2011, report for the German Ministry of Economics and Technology.

Rathmann, M., 2007. Do support systems for RES-E reduce EU-ETS-driven electricity prices? Energy Policy 35, 342-349.

Richter, J., 2011. DIMENSION - A Dispatch and Investment Model for European Electricity Markets, EWI Working Paper No.11/03.

Schleich, J., 2009. Barriers to energy efficiency: A comparison across the German commercial and services sector. Ecological Economics 68(7), 2150-2159.

Schleich, J., \& Gruber, E. 2008. Beyond case studies: Barriers to energy efficiency in commerce and the services sector. Energy Economics, 30(2), 449-464.

Sensfuß, F. et al., 2008. The merit-order effect: A detailed analysis of the price effect of renewable electricity generation on spot market prices in Germany, Energy Policy, vol. 36 (8), 3086-3094. 
Sijm, J., 2005. The interaction between the EU emissions trading scheme and national energy policies, in: Climate Policy, vol. 5 (1), 79-96.

Sorrell, S., 2003. Who Owns the Carbon? Interactions between the EU Emissions Trading Scheme and the UK Renewables Obligation and Energy Efficiency Commitment. SPRU Electronic Working Paper Series no. 100. Science and Technology Policy Reseach, University of Sussex (SPRU), Brighton.

Sorrell, S. \& Sijm, J., 2003. Carbon Trading in the Policy Mix, Oxford Review of Economic Policy, vol. 19 (3), 420-437.

Sorrell, S., Harrison, D. Radov, D., Klevnas, P. \& Foss, A., 2009. White certificate schemes: Economic analysis and interactions with the EU ETS, Energy Policy, vol. 37 (2009), 29-42.

Sorrell, S., O'Malley, E., Schleich, J. \& Scott, S., 2004. The Economics of Energy Efficiency-Barriers to Cost-Effective Investment. Edward Elgar, Cheltenham.

Trotignon, R. \& Delbosc, A., 2008. Allowance Trading Patterns during the EU ETS Trial Period: What does the CITL Reveal? Climate Report No. 13.

UBS, 2011. Carbon price to collapse, $€ 210 \mathrm{bn}$ wasted, November.

Wuppertal Institute et al., 2010. Erschließung von Minderungspotenzialen spezifischer Akteure, Instrumente und Technologien zur Erreichung der Klimaschutzziele im Rahmen der nationalen Klimaschutzinitiative (EMSAITEK-NKI).

\section{Annex}

Table 2: Modelled regions and countries

\begin{tabular}{ll} 
Region & Countries \\
\hline UKI & UK and Ireland \\
North & Sweden, Norway, Finland, Denmark \\
Baltic & Estonia, Latvia, Lithuania \\
Iberia & Spain and Portugal \\
CWE (Central Western EU) & France, Netherlands, Belgium and Luxembourg \\
CE (Central EU) & Germany and Austria \\
CEE (Central Eastern EU) & Poland, Hungary, Czech Republic and Slovakia \\
SCE (South Central EU) & Italy, Switzerland, Slovenia \\
SEE (South Eastern EU) & Bulgaria, Romania, Greece (Cyprus, Malta) \\
\hline
\end{tabular}

Table 3: Estimated final electricity demand in the EU in 2020 in BAU and EE scenarios

\begin{tabular}{lcccc}
\hline Source & Unit & BAU scenario & EE scenario & Savings (\%) \\
\hline $\begin{array}{l}\text { Roadmap 2050, PRIMES } \\
\text { (EC, 2011g) }\end{array}$ & Mtoe/a & 275 & 261 & 5.1 \\
$\begin{array}{l}\text { Energy [r]evolution } \\
\text { (EREC \& Greenpeace, 2012) }\end{array}$ & PJ/a & 11,317 & 10,547 & 6.8 \\
$\begin{array}{l}\text { World Energy Outlook 2012: } \\
\text { Current policies vs. 450 Scenario } \\
\text { (IEA, 2012) }\end{array}$ & Mtoe/a & 269 & 254 & 5.6 \\
$\begin{array}{l}\text { Power Choices } \\
\text { (Eurelectric, 2009) }\end{array}$ & TWh/a & 3209 & 3036 & 5.4 \\
\hline \hline
\end{tabular}


Table 4: Total estimated electricity and EUA cost impact on EU industry (bn€)

\begin{tabular}{lccccccccc}
\hline Scenario & $\mathbf{2 0 1 3}$ & $\mathbf{2 0 1 4}$ & $\mathbf{2 0 1 5}$ & $\mathbf{2 0 1 6}$ & $\mathbf{2 0 1 7}$ & $\mathbf{2 0 1 8}$ & $\mathbf{2 0 1 9}$ & $\mathbf{2 0 2 0}$ & cumulative \\
\hline BAU & 0.0 & 0.0 & 0.0 & 0.0 & 0.0 & 0.0 & 0.0 & 0.8 & 0.8 \\
EE5\% & 0.1 & 0.1 & -2.0 & -2.8 & -3.3 & -3.6 & -3.9 & -2.6 & -18.0 \\
BAU -355Mt & 8.0 & 8.5 & 9.1 & 9.5 & 9.9 & 10.6 & 10.8 & 12.5 & 78.8 \\
EE5\% -355Mt & 0.1 & 0.1 & -2.0 & -2.8 & -3.3 & -3.6 & -3.9 & -2.6 & -18.0 \\
EE10\% -355Mt & 0.1 & 0.1 & -3.3 & -4.8 & -5.8 & -6.5 & -7.6 & -7.3 & -35.2 \\
BAU -1400Mt & 15.8 & 16.8 & 18.0 & 18.5 & 19.4 & 20.7 & 21.6 & 23.8 & 154.6 \\
EE5\% -1400Mt & 12.6 & 13.3 & 12.1 & 12.3 & 13.2 & 14.1 & 15.2 & 17.2 & 110.1 \\
EE10\% -1400Mt & 7.2 & 7.6 & 4.8 & 4.3 & 4.0 & 3.8 & 3.1 & 4.1 & 38.9 \\
\hline \hline
\end{tabular}

